\title{
Estudio preliminar sobre métodos de detección de Microdochium oryzae en semillas de arroz
}

\author{
Susana A. Gutierrez ${ }^{1}$, Marcelo A. Carmona ${ }^{2}$ \& Erlei M. Reis ${ }^{3}$ \\ ${ }^{1}$ Cátedra de Fitopatología, Facultad de Ciencias Agrarias, Universidad Nacional del Nordeste, Sargento Cabral 2131 (3400), \\ Corrientes, Argentina; ${ }^{2}$ Facultad de Agronomia, Universidad de Buenos Aires, Ciudad de Buenos Aires, Argentina; ${ }^{3}$ Faculdade \\ de Agronomia e Medicina Veterinaria, Universidade de Passo Fundo, 99001-970, Passo Fundo, RS, Brasil
}

Autor para correspondencia: Susana A. Gutiérrez, e-mail: suarroz@yahoo.com.ar

\section{RESUMEN}

En ensayos conducidos en laboratorio, fueron evaluados cuatro métodos (Papel de filtro, Agar papa glucosado, Agar poroto y Agar extracto de malta), considerándose su eficiencia y sensibilidad para detectar Microdochium oryzae en semillas de arroz, variedad Fortuna. Los datos obtenidos fueron sometidos al análisis de varianza y las medias comparadas por con el test de Tukey. Entre los métodos probados, las mayores incidencias de Moryzae fueron detectadas en las semillas sembradas en medio conteniendo agar poroto. En ensayos de relevamiento sanitarios, cuantificación de la transmisión y de control, se debería usar preferencialmente este medio.

Palabras clave: Oryza sativa, escaldadura de la hoja, Monographella albescens

\section{ABSTRACT}

Preliminary study on detection methods of Microdochium oryzae in rice seeds

Four seed health methods (Blotter test, potato glucose agar, bean agar and malt agar) were evaluated for detection of Microdochium oryzae in rice seed, cultivar Fortuna, from Corrientes, Argentina. Data of seed incidence were submitted to analysis at the $5 \%$ significance level. The highest incidence of M. oryzae in seeds were detected on bean agar. Thus, this method should be recommend for detection and studies of transmission and control of $M$. oryzae in rice seeds.

Keywords: Oryza sativa, Monographella albescens, leaf scald of rice.

El cultivo de arroz (Oryza sativa L.) en Argentina es realizado en la región Litoral del país, siendo la provincia de Corrientes la principal productora con un total de 70000 has sembradas durante la campaña 2006-2007. Este cultivo es afectado por varias enfermedades de origen fúngico, entre las cuales, la escaldadura de la hoja es considerada una enfermedad de importancia creciente (Mazzanti de Castañón \& Gutiérrez, 2001). El agente causal es Microdochium oryzae (Hashioka \& Yokogi) Samuels \& I.C. Hallet (anamorfo) [sinónimos Gerlachia oryzae (Hashioka \& Yokogi) W. Gams y Rhynchosporium oryzae Hashioka \& Yokogi] cuyo teleomorfo es Monographella albescens (Thüm.) W.O. Parkinson, Sivan. \& C. Booth (Ou, 1985; Webster \& Gunnell, 1992).

La escaldadura de la hoja de arroz se caracteriza por presentar diferentes síntomas según los estadios de la planta de arroz (desde plántula, lesiones necróticas en láminas y vainas foliares, a manchado de glumas de granos de arroz). El síntoma que se manifiesta sobre las láminas foliares es el más común y de fácil reconocimiento en condiciones de campo (Mazzanti de Castañón \& Gutiérrez, 2001).

La enfermedad tiene amplia distribución mundial y está presente en varios países de América, Africa y Asia, tanto en cultivos bajo riego o en secano, ocasionando pérdidas considerables (Boratynski, 1979; Filippi \& Prabhu, 2005; Kimati et al., 2005; Ou, 1985; Wesbster \& Gunnell, 1982). También, el hongo se observa asociado a granos de arroz, integrando el complejo causal del manchado de las glumas de arroz (Gutiérrez, 2002). Las semillas infectadas y los restos de cultivos constituyen las principales fuentes de inóculo de la enfermedad (Mia et al., 1986; Ou, 1985).

En relevamientos de cultivos de arroz de la región y en análisis de sanidad rutinarios realizados con muestras de semillas de la región, se pudo constatar que la presencia del hongo $M$. oryzae ha ido aumentando en éstas últimas campañas agrícolas. Lo cual indica que la semilla de arroz cumple un rol fundamental en la diseminación del patógeno por medio de la misma. Por esta razón, se considera necesario contar con métodos de análisis de sanidad que permitan detectar en forma eficiente y rápida, la presencia del hongo en las semillas.

Con respecto a los métodos utilizados para su detección, se mencionan el del papel de filtro (Blotter test) y el del agar como los más sensibles para los análisis sanitarios, según lo informan los trabajos realizados por Boratynski (1979); Mia (1986); Mew \& Misra (1994) 
y Shetty \& Shetty (1988). Un medio semiselectivo fue desarrollado por Manandhar (1999), el cual es constituído por sucrosa como fuente carbonada y cloruro de potasio, con el agregado de varios antibióticos y un fungicida (Mancozeb). En otro estudio, Parkinson (1980) analizó el efecto de algunos medios de cultivo y de la luz sobre la morfología y el crecimiento del hongo, obtuvo buena esporulación en medio sólido con $1 \%$ de peptona y $0,25 \%$ de glucosa. También Thomas (1981), observó buena esporulación del hongo, en agar sucrosa, agar peptona y agar V8. Mew \& Misra (1994) informaron que M. oryzae es observado con frecuencia en las semillas de arroz.

El hongo M. oryzae es uno de los más importantes patógenos del arroz en Argentina, por eso se torna necesario contar con métodos sensibles para su detección. El objetivo de este trabajo fue comparar cuatro métodos de análisis sanitario de semillas, a fin de seleccionar el más sensible en la detección de $M$. oryzae asociado a semillas de arroz.

El ensayo fue conducido en el laboratorio de Fitopatología de la Facultad de Ciencias Agrarias, UNNE, Corrientes, Argentina. Se analizaron semillas de la variedad Fortuna, procedente de la localidad de Perugorría, Corrientes (Argentina) naturalmente infectada con $M$. oryzae y cosechada durante la campaña agrícola 2006/07.

Para el análisis se utilizaron los siguientes métodos: Papel de filtro (PF) (Blotter test); Agar papa glucosado (APG) 1,5\%, pH 6; Agar poroto (AP) 3\%, pH 6 y Agar extracto de malta (AEM) 2\%, pH 6 (Mathur \& Kongsdal, 2003; Mew \& Misra, 1994).

Para el método del papel de filtro se utilizaron cajas de Petri de $9 \mathrm{~cm}$ de diámetro, con tres discos de papel de filtro humedecidos con agua estéril, sobre los que se depositaron 25 semillas de arroz. Para los métodos agarizados, las semillas fueron inicialmente tratadas en una solución de hipoclorito de sodio al $2,5 \%$ por 10 minutos y posteriormente fueron lavadas 3 veces con agua estéril, durante 5 minutos cada uno (modificado de Mathur \& Kongsdal, 2003). Luego, las semillas fueron transferidas a cajas de Petri conteniendo el medio de cultivo correspondiente, con el agregado de un antibiótico (sulfato de estreptomicina). Se colocaron 10 semillas por caja de Petri.

Las cajas sembradas fueron incubadas a temperatura de $24 \pm 2^{\circ} \mathrm{C}$ con fotoperíodo de $12 \mathrm{~h}$ luz, $12 \mathrm{~h}$ oscuridad (NUV). Fueron utilizadas 400 semillas de arroz por método analizado. Después de 10-12 días de incubación, la identificación del patógeno se realizó utilizando los microscopios estereoscópico y compuesto. Se consideró semilla infectada a aquella que presentó las estructuras de fructificación del patógeno (esporodoquio y/o micelio).

La comparación estadística de los métodos de análisis fue realizada a través del análisis de la varianza y el test de Tukey con $5 \%$ de probabilidad. El hongo M. oryzae fue detectado en todos los métodos de análisis utilizados, registrándose los siguientes valores de incidencia: PF (4\%), AEM (4\%), APG (23\%) y AP $(41,25 \%)$ (Tabla 1$)$.

En las semillas enfermas, M. oryzae produjo los siguientes síntomas: muerte de raicillas y coleóptilos,
TABLA 1- Incidencia de Microdochium oryzae en semillas de arroz, variedad Fortuna, en diferentes métodos de sanidad

\begin{tabular}{|c|c|}
\hline Métodos & Incidencia $(\%)$ \\
\hline $\mathrm{PF}$ & $4 a$ \\
\hline AEM & $4 \quad \mathrm{a}$ \\
\hline APG & $23 \mathrm{~b}$ \\
\hline $\mathrm{AP}$ & $41,25 \mathrm{c}$ \\
\hline
\end{tabular}

Letras distintas indican diferencias significativas $(p<=0,05) \mathrm{PF}=\mathrm{Papel}$ de filtro; $\mathrm{AEM}=$ agar extracto de malta; $\mathrm{APG}=\mathrm{Agar}$ papa glucosado; $\mathrm{AP}=$ Agar poroto.

o inhibición de la germinación, desarrollando micelio algodonoso de color blanquecino y/o esporodoquios de color salmón sobre los tejidos enfermos (Figura 1). En los métodos utilizados se observó que el patógeno puede manifestarse de maneras diferentes sobre las semillas y/o sustratos, ya sea desarrollando abundante micelio aéreo, algodonoso blanquecino y escasa presencia de esporodoquios de color salmón, o solamente formando una masa cremosa de conidios de color salmón brillante, sin micelio (Figura 2). Cuando las semillas se sembraron en $\mathrm{PF}$, M. oryzae desarrolló pequeños esporodoquios de color salmón, aislados, sin micelio aéreo sobre las glumas de la semilla; en APG, AP y AEM, el hongo produjo micelio aéreo y/o esporodoquios típicos. Estas características culturales del hongo ya habían sido descritas por Parkinson (1980), quién encontró que la tasa de crecimiento y el grado de pigmentación de la masa de conidios estaban influenciadas por el tipo de medio de cultivo utilizado; aquellos medios que contenían arroz pulido y arveja, produjeron buen crecimiento del micelio y conidios, a diferencia de los medios con agar papa dextrosa que desarrollaron abundante micelio aéreo. En agar harina de maíz, el crecimiento del micelio fue sumergido, pero con abundante producción de conidios.

El análisis estadístico muestra que el método AP fue significativamente más eficiente $(\mathrm{p}<0,05)$ que $\mathrm{PF}, \mathrm{AEM}$ y APG, para la detección del patógeno en semillas; además se comprobó que al utilizarse dicho método, también se desarrolla Alternaria padwickii (synonym Trichoconis padwickii), considerado actualmente un patógeno importante de las semillas de arroz. Con respecto a los métodos de PF y AEM, no se observó diferencias significativas entre ambos. Por lo tanto y de acuerdo con los resultados obtenidos en este trabajo, el medio de agar poroto resultó ser el más sensible para la detección de M. oryzae en semillas de arroz. Este método debería recomendarse en relevamientos de sanidad de semillas, cuantificación de transmisión semillasplántulas y de control químico. Sin embargo, más estudios son necesarios para establecer la importancia del uso del medio de agar poroto en muestras de semillas de diferentes variedades y con diferentes niveles de infección. 

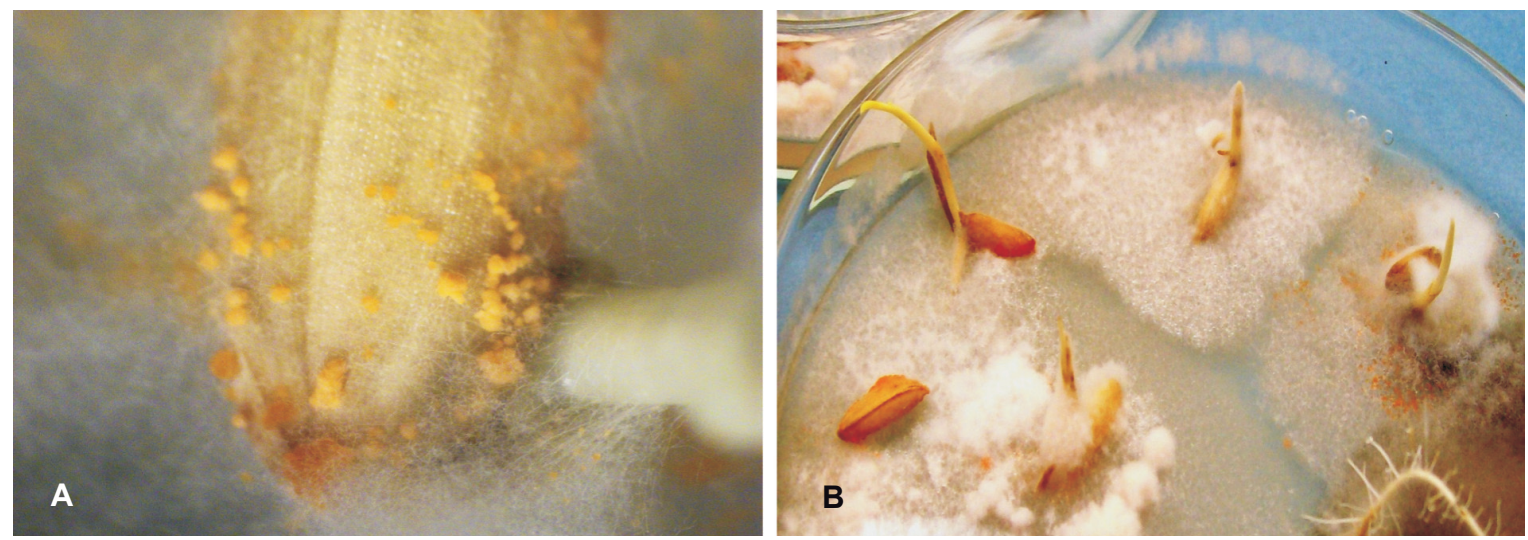

FIGURA 1 - A. Esporodoquios de Microdochium oryzae sobre semillas de arroz (método de agar poroto); B. Síntomas en semillas de arroz causados por M .oryzae (método de agar poroto).

\section{REFERENCIAS BIBLIOGRAFICAS}

Bedendo IP, Prabhu AS (2005) Doenças do arroz Oryza sativa Capitulo 12. Em: Kimati H, Amorin L, Rezende JAM, Bergamin Filho A, Camargo LEA (Eds.) Manual de Fitopatologia. Vol 2. Doenças das plantas cultivadas. $4^{\text {a }}$. Ed. São Paulo SP. Ceres. pp. 79-90.

Boratynski TN (1979) La escaldadura de la hoja de arroz Rhynchosporium oryzae Hashioka e Ikegami, en Costa Rica. Agronomía Costarricense 3:21-27.

Filippi MC, Prabhu AS (2005) Escaldadura do Arroz e seu controle Circular Técnica 72. Santo Antônio de Goiás GO. Embrapa Arroz e Feijão.

Gutiérrez SA, Cúndom MA, Mazzanti de Castañón MA (2002) Hongos en semillas de arroz del noreste de Argentina. Fitopatología 37:156-163.

Gutiérrez SA (2002) Micoflora asociada al manchado del grano de arroz. XI Jornadas Fitosanitarias Argentinas, Río Cuarto, Córdoba. p. 29.

Hastings de Gutiérrez L (1960) Leaf scald of rice, Rhynchosporium oryzae, in Costa Rica. Plant Disease Reporter 44:294-295.

Manandhar B (1999) Isolation of Microdochium oryzae and Pinatubo oryzae from rice seeds and their survival on stored seeds. European Journal of Plant Pathology 105:139-145.
Mathur SB, Kongsdal O (2003) Common laboratory seed health testing methods for detecting fungi. $3^{\text {rd }} \mathrm{Ed}$. Copenhagen, Denmark.

Mazzanti de Castañón MA, Gutiérrez SA (2001) Enfermedades del cultivo del arroz en Argentina. Fitopatología Brasileira 26(Supl.):471.

Mia MAT, Safeeulla KM, Shetty HS (1986) Seed-borne nature of Gerlachia oryzae, the incitant of leaf scald of rice in Karnataka. Indian Phytopathology 39:92-93.

Mew TW, Misra JK (1994) (Eds.) A Manual of Rice Seed Health Testing. Manila, Philippines, International Rice Research Institute.

Parkinson VO (1980) Cultural characteristics of the rice leaf scald fungus, Rhynchosporium oryzae. Transactions of the British Mycological Society 74:509-514.

Shetty SA, Shetty HS (1988) Development and evaluation of methods for the detection of seed-borne fungi in rice. Seed Science and Technology 16:693-698.

Thomas MD (1981) Preliminary studies on isolation and means of spread of the rice leaf scald fungus in Sierra Leone. International Rice Research Notes 6:13-14.

Webster RK, Gunnell PS (Eds.) (1992) Compendium of rice diseases. Saint Paul MN. APS Press.

$\overline{\text { Recebido } 19 \text { Setembro } 2008 \text { - Acceptado } 20 \text { Fevereiro } 2009 \text { - TPP } 7129}$

Editores Associados: David Jaccoud Filho, José C. Machado 